\title{
Total eklem replasmanlı hastalarda dental işlemler için antibiyotik profilaksisi
}

\author{
Antibiotic prophylaxis applications in dental patients \\ who had undergone total joint replacement
}

\author{
Sermet İnal ${ }^{1}$, Hasan Hatipoğlu ${ }^{2}$, Hüseyin Gencay Keçeli ${ }^{3}$ \\ 1Dumlupınar Üniversitesi, Tıp Fakültesi, Ortopedi ve Travmatoloji Anabilim Dalı, Kütahya, Türkiye \\ 2Dumlupınar Üniversitesi, Diş Hekimliği Fakültesi, Periodontoloji Anabilim Dalı, Kütahya, Türkiye \\ 3Kırıkkale Üniversitesi, Diş Hekimliği Fakültesi, Periodontoloji Anabilim Dalı, Kırıkkale, Türkiye
}

Oral bakteriler, günlük ağız hijyeni uygulamaları ve dental tedaviler sırasında kana karışabilmekte ve enfeksiyona neden olabilmektedir. Bu durum özellikle enfektif endokardit için oldukça yoğun şekilde tartışılmıştır. Total eklem replasmanı yapılmış bireylerdeki dental girişimler esnasında önerilen antibiyotik profilaksi uygulamaları da tıp ve diş hekimliği alanına mensup akademisyenlerin oluşturduğu bilimsel komitelerce birçok kez görüşülmüştür. Profilaksi konusunda bu tip mevcut tartışmaların bulunması ideal hasta takibi ve istenmeyen enfektif durumların önüne geçilebilmesi bakımından önem teşkil etmektedir. Bu derlemenin amacı total eklem replasmanı yapılan kişilerdeki diş hekimliği uygulamaları sırasında tercih edilen mevcut antibiyotik profilaksisi uygulamalarını ele almak ve ayrıntılarını irdelemektir.

Anahtar sözcülkler: bakteriyemi; artroplasti; bakım, diş; antibiyotikler
Oral bacteria may spread to the blood circulation during daily oral hygiene activities and dental treatments and may lead to infections. This important situation was fairly well discussed for infective endocarditis. The guidelines for antibiotic prophylaxis treatment of dental patients with total joint replacement are discussed on several occasions by scientific committees of medical and dental organizations. Presence of discussions about the antibiotic prophylaxis is important for an ideal patient screening and prevention of undesirable infections. The purpose of this review is to discuss the current approaches and details on antibiotic prophylaxis in dental patients who had undergone total joint replacement.

Key words: bacteremia; arthroplasty; care, dental; antibiotics

dikkat çekilmektedir ki, bunlardan biri de dental girişim gerektiren hastalardaki antibiyotik baskısı altındaki yaklaşımdır.

Tarihi geçmişi 1700 'lü yıllara dayanan total kalça artroplastisinde 1950'li yıllara gelindiğinde, ameliyat sonrasında gelişen enfeksiyon oranının \% 12'lere yaklaştığı görülmektedir. ${ }^{[3-5]}$ Total eklem replasmanı yapılan hastalardaki ilk üç ay içinde gelişen enfeksiyonlar "erken dönem protez enfeksiyonu", üç ile yirmi dört ay arasında gelişen enfeksiyonlar ise "gecikmiş dönem protez enfeksiyonu" olarak kabul edilmektedir. ${ }^{[6]}$ Erken ve gecikmiş dönem protez enfeksiyonlarının genellikle implantasyon sırasında kontaminasyonla oluştuğu düşünülmektedir. Yirmi dört aydan sonra gelişen enfeksiyonlar ise "geç dönem protez enfeksiyonları" olarak adlandırılmaktadır. ${ }^{[6]}$ Geç

- İletişim adresi: Yrd. Doç. Dr. Sermet İnal, Dumlupınar Üniversitesi, Tıp Fakültesi, Ortopedi ve Travmatoloji Anabilim Dalı, Merkez Kampus, Tavşanlı Yolu 10. km, Kütahya, Türkiye Tel: 0274 - 265 20 31/1715 Faks: 0274 - 2652277 e-posta: sermetinal@yahoo.com.tr

- Gelis tarihi: 28 Mart 2013 Kabul tarihi: 25 Haziran 2013 
dönem protez enfeksiyonlarının ise uzak bir odaktan hematojen yolla bakterinin yayılması sonucu oluştuğu kabul edilmektedir. ${ }^{[6]}$ Protez enfeksiyonlarında en sık sorumlu tutulan mikroorganizmalar; koagülaznegatif stafilokoklar, Staphilococcus aureus, streptokoklar, enterokoklar, gram negatif basiller ve çeşitli anaeroblar olarak belirtilmiştir. ${ }^{[6]}$

Mikroorganizmaların çokluğu ve yayılım yolu göz önünde tutulduğunda, ameliyat içi antibiyotik kullanımının önemi ortaya çıkmaktadır. Operasyon sahasına ait laminar hava akımı gibi yaranın kontaminasyonunu azaltan özel sistemler, özel cerrahi elbise kullanımı, operasyonlarda antibiyotik emdirilmiş çimento kullanımı ve bu gibi diğer tekniklerin kullanılmaya başlanmış olması ile son 20 yılda, ameliyatın hemen sonrasında, ameliyat sırasındaki kontaminasyona bağlı gelişebilecek protez enfeksiyon oranının \%1-2'lere düştüğüü görülmektedir. ${ }^{[2,7-9]} \mathrm{Geç}$ dönem protez enfeksiyonu geliştiğinde, öncelikle yara yerinden alınan kültürler doğrultusunda enfeksiyon hastalıkları uzmanlarının da kanaatleriyle, antimikrobiyal tedavi, başarısızlık durumunda ise cerrahi olarak protezin çıkarılması, sonrasında antibiyotik tedavisine sistemik olarak devam edilmesi, yerine geçici bir antibiyotikli yer tutucu aparat koyulması, belli bir süre beklenip mikrobiyolojik biyokimyasal parametrelerde düzelme sağlandıktan sonra yeni bir cerrahi prosedürle protezin revizyonu gibi bir tedavi süreci izlenmektedir. Bu tedavi süreçleri sırasında, ilaç kullanımına bağlı olarak hastalarda allerjik reaksiyonlar ve ilaç toksisiteleri ile operasyonun kendisinin meydana getirebileceği morbid veya mortal durumlar olabilmektedir.

\section{Diş HEKIMLiĞi UYGULAMALARI, BAKTERIYEMi VE TOTAL EKLEM REPLASMANI}

Bakteriyemi, basit bir şekilde, kan dolaşımında mikroorganizmaların bulunması şeklinde tanımlanabilir; normal şartlar altında steril kabul edilen kan dolaşımına vücuttaki herhangi bir bölgede gelişen bir cerrahi yara ya da enfeksiyon alanından bakterilerin yayılması sonucunda ortaya çıkmaktadır. Bakteriyemi oluşumunun ardından, bu bakteriler çoğu kez damarlarda belli bir süre varlığını devam ettirdikten sonra dolaşımdan uzaklaştırılmaktadır. Ancak özellikle vücutta herhangi bir yapay ünite (prostetik kalp kapağı vb.) varlığında, mikroorganizmalar dolaşımdan bu alanlara geçerek kolonize olabilmekte ve enfektif endokardit gibi lokal enfeksiyonlar meydana getirebilmektedir.

Son dönemlerde ağız sağlı̆̆ının genel vücut sağığı ile ilişkisi oldukça iyi tanımlanmıştır. İlgili literatür incelendiğinde ağız sağlığının diyabet, kardiyovasküler hastalıklar, pulmoner enfeksiyonlar, metabolik sendrom ve olumsuz hamilelik süreci ile ilişkisinin de birçok kez irdelendiği görülmektedir. ${ }^{[10,11]}$ Enfektif endokardit oluşumunda oral bakterilerin ve dental uygulamaların rolü uzun süredir tartışılmakta ve bu tartışmalarda ağız boşluğunun sahip olduğu özellikler ve bu boşlukta gerçekleşen hücresel ve moleküler düzeydeki karmaşık ilişkiler detaylı biçimde ortaya konmaktadır. [12] Halbuki eklem protezi enfeksiyonları için daha az sayıda araştırma mevcuttur.

Son dönemde inceleme metodlarının gelişmesi ile normal ağız florasında 700'den fazla bakteri türü ve suşu saptanmıştır. ${ }^{[13]}$ Diş yüzeylerine tutunmuş olan bakterilerin organize olarak meydana getirdiği biyofilme dental plak adı verilmektedir. Dental plak diş yüzeyine yerleştikten sonra, etkin ağız bakımı uygulamaları ve/veya profesyonel diş temizliği işlemleri ile bölgeden uzaklaştırılabilmektedir. Plak fonksiyon ve şekil bakımından organize ve karmaşık bir biyofilm yapısı ortaya koymaktadır. ${ }^{[14,15]} 1 \mathrm{~mm}^{3}$ dental plak yaklaşık $1 \mathrm{mg}$ ağırlığında olup içeriğinde 200 milyondan fazla bakteri mevcuttur. ${ }^{[16,17]}$ Sağlıklı bireylerden elde edilen dental plak örnekleri incelendiğinde, firmikütler (Streptokoklar, Gemella, Eubakterium, Selenomonas, Veillonella vb.), aktinobakteriler (Aktinomices, Atopobium, Rothia vb.), proteobakteriler (Neisseria, Eikenella, Campylobakter), bakteroidesler (Porphyromonas, Prevotella, Capnocytophaga vb.) ve fusobakteriler (Fusobakterium, Leptotrichia) gibi birçok mikroorganizmaya rastlanmıştır. ${ }^{[13]}$ Periodontal hastalık diş ve çevre destek dokularını içine alan, etkeni dental plak olan iltihabi bir hastalık grubudur. Periodontal hastalıkla beraber oluşan enflame dişeti dokusu; tümör nekroz edici faktör-ó, interlökin $1-\beta$, prostaglandin $\mathrm{E}_{2}$ ve interferon- $\gamma$ gibi birçok sayıda iltihabi mediyatör üretip vücudun genel enflamasyon yükünü arttırmaktadır. ${ }^{[11]}$ Dental plak ve onun etkisi ile gelişen periodontal hastalıkla ilgili tüm bu veriler ağız boşluğunda oldukça yoğun bir bakteriyel faaliyetin var olduğunu ve bunun sonucunda iltihabi hastalıkların meydana geldiğini göstermektedir. Ağızdaki yaraların, günlük oral hijyen uygulamalarının ve dental tedavilerin önemli oranda bakteriyemiye neden olabileceği gösterilmiştir. ${ }^{[10,18]}$ Diş firçalama, diş ipi kullanma gibi oral hijyen uygulamaları ya da çiğneme gibi günlük rutin oral aktiviteler neticesinde oluşan bakteriyeminin kısa süreli ve düşük şiddette olduğu belirtilmiştir. ${ }^{[19]}$ Ancak kümülatif olarak düşünüldüğünde günlük oral aktivitelerdeki bakteriyeminin dental girişimler ile oluşandan daha fazla olduğu görülmektedir. ${ }^{[20]}$ Guntheroth'a göre ${ }^{[21]}$ bir aylık süre içinde sadece tek bir diş çekimi yapıldığı varsayıldığında oluşan bakteriyeminin 6 ile 30 dakika kadar sürdüğü, buna karşın bir aydaki kümülatif oral 
fizyolojik kaynaklı olan ya da oral hijyen uygulamaları neticesinde oluşan bakteriyeminin ise 5370 dakika olduğu belirtilmiştir. (Tek diş çekimine kıyasla 895-179 kat fazla). Seymour ve ark. ${ }^{[18]}$ yayımlamış oldukları gözden geçirme yazılarında, günlük oral aktiviteler ile bazı dental girişimlerin benzer düzeyde bakteriyemiye neden olabileceğini belirtmişlerdir. Diş çekimlerinde \%51-100 arasında, (tek diş çekimi: \%51, çoklu diş çekimi: \% 68-100), periodontal cerrahi uygulamalarında \%36-88 arasında (periodontal flep cerrahisi: $\% 36-88$, gingivektomi: \%83), endodontik tedavi uygulamalarında \% 0-54 arasında (intrakanal enstrümantasyonun yapıldığı olgularda \% 0-31, ekstrakanal enstrümantasyonun yapıldığı olgularda: \% 0-54) ve endodontik cerrahi işlemlerde \%33-83 oranında bakteriyemi yaygınlığı bildirilmiştir. Çiğneme gibi günlük aktiviteler ve oral hijyen uygulamalarında ise \%0-58 arasında (çiğneme esnasında: \%17-51, diş firçalama: \%0-26, diş ipi uygulamaları: \%20-58 ve ara yüz temizliğinde kürdan kullanımı: \%20-40) seyreden bakteriyemi yaygınlığı bildirilmiştir. Roberts ${ }^{[20]}$ makalesinde, dental açıdan günlük oral aktiviteler ve dental girişimler sırasında klinik olarak izlenebilecek belirgin bir kanama olmasa da bakteriyeminin oluşabileceğini bildirmiştir. Dental girişimlerin, bu konudaki önemi açısından, girişimsel gastrointestinal ve ürogenital işlemlere göre bakteriyemiyi daha yüksek oranda tetiklediği belirtilmektedir. ${ }^{[22]}$

Avrupa Kardiyoloji Derneği (European Society of Cardiology - ESC) enfektif endokardit tanı, önleme ve tedavi kılavuzunda 2009 yılında yaptığı güncellemeye göre, ağız sağı̆̆ı iyi olmayan hastalarda, oral girişimlerden bağımsız olarak bakteriyeminin gözlenebildiğinin altı çizilmiştir. Ağız sağlı̆̆ı kötü olan hastalarda, iyi olanlara göre, oral girişim sonrasında bakteriyemi oranlarının daha yüksek olduğu belirtilmiştir. ${ }^{[19]}$ Buna benzer olarak da Lockhardt ${ }^{[23]}$ yazısında, ağız hijyeninin ve periodontal tablonun önemine değinmiştir. Total eklem replasmanı ile ilgili kılavuzlarda da ağız hijyeninin önemine vurgu yapıldığı görülmektedir. ${ }^{[24,25]}$ Literatürde yer alan birçok yayında da, ameliyat sonrası protez enfeksiyonlarının oluşumunda dental süreçlerin rolü sıklıkla tartışılmaktadır. ${ }^{[26,27,28]}$ Barrington ve Barrington, ${ }^{[29]}$ total eklem artroplastisi endikasyonu bulunan 100 hastanın (75 primer cerrahi yapılacak, 25 revizyon yapılacak hasta) \%23'ünde tedavi edilmemiş dental patolojiye (ortalama olarak 2,9 çürük diş) rastlamışlardır. Bu hastaların dental tedavisi sağlanıp ortopedik cerrahisinden sonra, ilk 90 günde protez enfeksiyonunun gelişmediği saptanmıştır. ${ }^{[29]}$ Öte yandan, yapılan bir değerlendirmede de dental işlemler ile protez eklem enfeksiyonu arasında anlamlı bir ilişki ortaya koyulamadığı ve total artroplasti geçiren kişilerde profilaktik antibiyotik kullanımının tartışmalı olduğu belirtilmiştir. ${ }^{[30]} 2010$ yılında yayınlanmış bir vaka kontrol çalışmasında Berbari ve ark. ${ }^{[31]}$ tarafından protez eklem enfeksiyonuna sahip olan ve olmayan 339'ar hasta incelenmiş, ne düşük ne de yüksek riske sahip dental süreçlerin artmış prostetik enfeksiyon oranı ile ilişkisi olduğu saptanmıştır. Ayrıca bu çalışmada dental prosedürler öncesi antimikrobiyal ilaçların kullanılması da riski azaltma yönünden anlamlı bulunmamıştır.

\section{TOTAL EKLEM REPLASMANI VE DENTAL ANTIBIYOTIK PROFILAKSI UYGULAMALARI}

1970 ve 1980 'li yılların başında ortopedi camiası, dental kaynaklı bakteriyeminin protez enfeksiyonunun bir kaynağı olarak rolü olabileceği üzerinde odaklanmaya başlamış ve buna yönelik girişimleri tartışmışlardır. ${ }^{[26,32]}$ Mevcut tartışmaların ışı̆ıında, 1997 yılında Amerikan Diş Hekimleri Birliği (American Dental Association; ADA), Amerikan Ortopedik Cerrahlar Akademisi (American Academy of Orthopeadic Surgeons; AAOS) ve konuyla ilgili deneyimli enfeksiyon hastalıkları uzmanlarının katkısıyla, dental tedavi görecek total eklem replasmanı yapılmış bireyler için tavsiyelerde bulunulmuştur. ${ }^{[24]}$ Bu öneriler daha sonra 2003 yılında güncellenmiştir. ${ }^{[25]} 2003$ yılında güncellenen bu kılavuzda, profilaksi uygulanması gereken potansiyel hasta risk grupları yeniden tanımlanmıştır. 1997 ve 2003 AAOS/ADA önerilerinde; pin, plak ve vida uygulamalarında total eklem protezi olan ve dental girişim yapılması planlanan hastalar için antibiyotik profilaksisi yapılmasına gerek görülmemiştir. ${ }^{[24,25]}$ AAOS/ADA, 2003 yılında yaptıkları toplantılarda, total eklem replasmanı yapılmış ve dental girişim yapılması düşünülen hastalar için antibiyotik profilaksisi konusunda artmış risk altında bulunan hasta gruplarını tanımlamışlardır. Buna göre hematojenik kökenli total eklem enfeksiyonu açısından potansiyel artmış risk altında bulunan gruplar; operasyondan sonra iki yılını tamamlamamış total eklem replasmanı yapılanlar, enflamatuar artropatileri (romatoid artrit, sistemik lupus eritematosuz vb.) olanlar, ilaç ya da radyasyonun tetiklediği bağışıklık sistemi baskılanmış ya da yetmezliği olan hastalar, geçirilmiş protez eklem enfeksiyonu hikayesi olanlar, malnütrisyonu olanlar, hemofilili hastalar, HIV (+) enfeksiyonlu bireyler, insülin bağımlı diyabet (Tip 1) veya malignensisi bulunan komorbiditeli hastalar olarak sıralanmaktadır. ${ }^{[25]}$

Yine bu kılavuzda yüksek bakteriyemi insidansına sahip dental girişimler tanımlanmıştır. Bu işlemler diş çekimi, cerrahi ve cerrahi olmayan dişeti 
tedavileri, dental implant uygulamaları ve avülse dişin replantasyonu, dişin kök ucu (apeks) ötesine kadar ilerleyebilecek endodontik tedaviler, ortodontik bant yerleştirilmesi, intraligamenter ve intraosseöz lokal anestezi uygulamaları ile kanamanın beklendiği diş ya da implant yüzey temizliği süreçleridir. Öte yandan, düşük bakteriyemi sıklığına sahip dental girişimler ise, yenileyici dental işlemler, intraosseöz ve intraligamenter uygulama dışındaki lokal anestezi işlemleri, kanal içi endodontik tedaviler, rubber dam (dental tedavi sürecinde, dişin sıvılardan izolasyonunu sağlayan ince lastik örtü) yerleştirilmesi, cerrahi sonrası sütür alınması, hareketli ortodontik ve prostetik aparatların yerleştirilmesi, ağız içi ölçülerin ve ağız radyografilerinin alınması, flor uygulamaları, ortodontik aparatların uyumlanması olarak listelenmiştir. ${ }^{[25]}$ Buna göre antibiyotik profilaksisi, hematojenik kökenli total eklem enfeksiyonu açısından potansiyel artmış riske sahip hasta gruplarında, yüksek bakteriyemi sıklığına sahip olduğu belirtilen dental girişimler için önerilmekte, düşük bakteriyemi sıklığına sahip olduğu belirtilenler için önerilmemektedir. ${ }^{[25]}$ Düşük bakteriyemi insidansına sahip dental işlemler için, yalnız klinik olarak belirgin kanamanın beklendiği vakaların antibiyotik profilaksisi için endikasyon oluşturabileceği belirtilmektedir. ${ }^{[25]}$ 2003-AAOS/ADA kılavuzunda önerilen antibiyotik profilaksi rejimleri, penisilin allerjisinin olup olmamasına ve penisilinin ağızdan alınıp alınamamasına göre gruplandırılmıştır (Tablo 1).[ ${ }^{25]}$

2009 yılında diş hekimliği ya da ortopedi dışı dalların ortak kararı olmaksızın AAOS, "Eklem Replasmanlı Hastalarda, Bakteriyemi İçin Antibiyotik Profilaksisi" başlıklı bir bildirimde bulunmuştur. ${ }^{[2]} \mathrm{Bu}$ bildiri, yazarların fikirlerine göre geliştirilen, eğitimsel bir araç olarak sunulmuş̧tur. Okuyucuların, verilen bildirime göre kendilerinin yorumuyla antibiyotik profilaksisinin yapılıp yapılmaması konusunda kendi sonuçlarına ulaşabilmeleri amaçlanmıştır. 2009 yılı
AAOS bildirisi, daha önce yayımlanan 2003-AAOS/ ADA kılavuzuna göre, oldukça anlamlı değişiklikler içermektedir. AAOS-2009 bildirisine göre:

- Protez eklem replasmanı olan

- Bağışıklık sistemi baskılanmış ya da yetmezliği olan

- Romatoid artrit ve sistemik lupus eritematosuz gibi enflamatuar artropatisi olan

- illaç ya da radyasyonun tetiklediği bağışıklık sistemi baskılanmış

- Diabetes mellitus'lu

- Obez

- HIV enfeksiyonu ve sigara kullanan komorbiditeli

- Geçirilmiş protez eklem enfeksiyonu öyküsü olan

- Malnütrisyonu olan

- Hemofilili

- İnsülin bağımlı (Tip 1) diabetes mellitusu bulunan

- Malignite ve mega protezi olan

tüm hastalar, hematojen yayılım açısından potansiyel artmış riskli hasta olarak kabul edilmiştir. ${ }^{[2]} 1997$ ve 2003 yılındaki toplantılarda total eklem protez ameliyatından sonraki ilk iki yıl hematojenik total eklem enfeksiyonu için potansiyel artmış risk olarak kabul edilirken,[24, 25] 2009 yılındaki toplantıda, hematojenik total eklem enfeksiyonu için tüm protez eklem replasmanı yapılanlar potansiyel artmış risk grubunda kabul edilmişlerdir. ${ }^{[2]}$ Ayrıca AAOS-2009 bildirisinde, diğer kılavuzlardan farklı olarak, yüksek ve düşük bakteriyemi sıklığına sahip dental girişimlerden bahsedilmemektedir.

Bunun dışında, AAOS-2009 ancak sinoviyal eklem ile ilişkili olmayan pin, plak ve vida ile ortopedik donanım uygulamalarında antibiyotik profilaksisi uygulamasına ihtiyaç duyulmadığını belirtmiştir. AAOS2009 bildirisinde, antibiyotik profilaksi rejimlerinde

Tablo 1. AAOS ve ADA tarafından 2003 yılında dental işlemlerde önerilen profilaktik antibiyotik rejimi*[25]

\begin{tabular}{|c|c|c|c|}
\hline Allerji durumu - alınma şekli & Antibiyotik türevi & Zamanlama & Doz \\
\hline Penisilin allerjisi yoksa - oral alınabiliyorsa & $\begin{array}{l}\text { Amoksisilin } \\
\text { Sefaleksin } \\
\text { Sefradin }\end{array}$ & & $2 \mathrm{gr}, \mathrm{PO}$ \\
\hline Penisilin allerjisi yoksa - oral alınamıyorsa & $\begin{array}{l}\text { Ampisilin } \\
\text { Sefazolin }\end{array}$ & $\begin{array}{l}\text { Dental işlemden } \\
1 \text { saat önce }\end{array}$ & $\begin{array}{l}2 \mathrm{gr}, \mathrm{IM} / \mathrm{IV} \\
1 \mathrm{gr}, \mathrm{IM} / \mathrm{IV}\end{array}$ \\
\hline Penisilin allerjisi varsa - oral alınabiliyorsa & Klindamisin & & $600 \mathrm{mg}, \mathrm{PO}$ \\
\hline Penisilin allerjisi varsa - oral alınamıyorsa & Klindamisin & & $600 \mathrm{mg}, \mathrm{IV}$ \\
\hline
\end{tabular}


Tablo 2. AAOS tarafından 2009 yılında dental işlemlerde önerilen profilaktik antibiyotik rejimi ${ }^{2]}$

\begin{tabular}{|c|c|c|c|c|}
\hline Uygulanacak işlem* & Antimikrobiyal ajan & Zamanlama & Doz & Süre \\
\hline Dental işlemler & $\begin{array}{l}\text { Sefaleksin } \\
\text { Sefradin } \\
\text { Amoksisilin }\end{array}$ & $\begin{array}{c}\text { Dental işlemden } 1 \text { saat } \\
\text { önce }\end{array}$ & $2 \mathrm{gr}, \mathrm{PO}$ & $\begin{array}{l}\text { İşlem sonrasında } 24 \text { saat } \\
\text { içinde durdurulur. } \\
\text { Birçok ayakta tedavi için } \\
\text { tek doz yeterlidir. }\end{array}$ \\
\hline
\end{tabular}

allerji varlığında ya da ilacın oral yoldan alınamadığı durumlar için profilaksi yönetimi konusunda bir bilgiye rastlanmamıştır (Tablo 2). ${ }^{[2]}$ AAOS-2009 bildirisinin son kısmında, nihai kararın hekimde olduğunu ve hekimin profilaktik antibiyotik uygulamasının kararını, antibiyotik toksisitesi, allerji, mikrobiyal direnç gibi durumları göz önünde tutarak, kendi öngörüsü ile vermesini önermiştir. ${ }^{[2]}$

2012 yılında AAOS ve ADA beraber yaptıkları değerlendirmede, dental tedavi görecek kalça ve diz protez eklem implantı bulunan bireylerde rutin antibiyotik profilaksi uygulamalarının gözden geçirilebileceğine, protezli eklem / ortopedik implantlı bireylerde topikal oral antimikrobiyal ajanların etkilerinin tartışmalı olduğuna ve bu bireylerde uygun oral hijyenin önemine işaret etmişlerdir. ${ }^{[33]}$

\section{SONUÇ VE ÖNERILER}

Total eklem replasmanı, çoğunlukla diz veya kalça ekleminin dejenerasyonu (genellikle primer artrozu) sonucu gelişen ve enflamasyondan kaynaklanan ağrılı ve kısıtlayıcı hareketin tedavisine yönelik olarak uygulanmaktadır. Total eklem replasmanı geçiren hastaların maruz kaldığı problemlerden birisi, geç dönem protez enfeksiyonudur. Bu tip enfeksiyonların önlenmesi ve giderilmesi, hasta sağlığı ve ömrü açısından kritik bir öneme sahiptir.

Amerikan Kalp Derneği (American Heart Association - AHA), Ingiltere Antimikrobiyal Kemoterapi Derneği (British Society of Antimicrobial Chemotherapy - BSAC), ADA ve AAOS gibi çeşitli bilimsel kurum ve kuruluşlar, çeşitli istenmeyen klinik durumların önlenmesine ve kullanılacak antibiyotik profilaksisine yönelik kılavuzlar hazırlayarak, sağlık hizmeti sunan kişilerin günlük uygulamalarına yardımcı olmaktadırlar. Ancak uygulamada son karar, hastadan sorumlu hekimler tarafindan verilmektedir. ideal hasta takibi ve işlemler sonrasında hastalarda meydana gelebilecek olumsuzlukların en aza indirilmesi açısından, mevcut kılavuzlardaki veriler göz önünde bulundurulmalıdır. Kılavuz ve önerilerdeki farklı yorumlar klinisyeni bu konudaki uygulamalarda zora sokabilmektedir. Dolayısıyla bu konunun oldukça geniş bir perspektif ile ele alınmasında yarar vardır. Özellikle en son olarak yayımlanan AAOS-2009 bildirisindeki profilaktik antibiyotik uygulamaları konusunda, ilgili tıp ve diş hekimliği dallarınca ciddi eleştiriler yapılmaktadır. ${ }^{[34,35]}$ Eleştirmenlere göre AAOS2009 uygulamaları antibiyotik tüketiminde ciddi bir artışı beraberinde getirmektedir. Antibiyotiklerin istenmeyen yan etkilere neden olabilmesi, çapraz direnç geliştirebilme riskinin bulunması ve tedavi maliyeti gibi önemli hususların sorgulanmasının şart olduğu belirtilmiştir. AAOS-2009 bildirisine eleştirel bir gözle bakan Amerikan Oral Tıp Akademisi (American Academy of Oral Medicine - AAOM) tarafindan yapılan bir değerlendirmede, 2003-AAOS/ADA önerilerinin benimsenmesiyle birlikte, aşırı antibiyotik tüketiminin, bunlara bağlı reaksiyonların ve ciddi bir maliyetin önüne geçilebileceği belirtilmiştir. ${ }^{[7]}$

Görüleceği üzere farklı dayanakları bulunan mevcut tartışmalar bu konunun daha yoğun tartışılması gerektiğini ortaya çıkarmaktadır.

Dikkat çekilmesi gereken bir husus da, günlük yaşamda karşılaşılan bakteriyeminin engellenemeyeceğidir. Dental açıdan bakıldığında, optimum oral hijyenin sağlandığı bir ağız boşluğunda bu riskin azalacağı muhakkaktır. Dolayısıyla, günlük oral hijyen uygulamalarının ve düzenli diş hekimliği kontrollerinin önemi daha fazla ortaya çıkmaktadır.

Hastanın kendisine has olabilen sağlık problemleri göz önünde tutularak, yapılacak dental müdahale öncesinde kılavuzların yönlendirmede eksik kaldığı durumlarda ve en ufak şüphede dahi konsültasyon mekanizmasının çalıştırılması önemlidir.

Bu verilerin ışığında ülkemizin bilimsel kurum ve kuruluşlarının işbirliği ile bu tarz klinik durumlar için bu öneriler tartışılmalı ve diş hekimleri, ortopedistler ve enfeksiyon hastalıkları uzmanları arasındaki işbirliğinin güçlendirilmesine yönelik adımlar atılmalıdır. 


\section{KAYNAKLAR}

1. Kurtz S, Ong K, Lau E, Mowat F, Halpern M. Projections of primary and revision hip and knee arthroplasty in the United States from 2005 to 2030. J Bone Joint Surg Am 2007;89(4):780-5.

2. American Academy of Orthopeadic Surgeons. Antibiotic Prophylaxis for Patients after Total Joint Replacement. Information Statement from the American Academy of Orthopaedic Surgeons. Antibiotic prophylaxis for bacteremia in patients with joint replacements. Information Statement-1033. February 2009. Online, Accessed June 15, 2013. http:// orthodoc.aaos.org/davidgrimmmd/Antibiotic Prophylaxis for Patients after Total Joint Replacement.pdf

3. Gomez PF, Morcuende JA. Early attempts at hip arthroplasty-1700s to 1950s. lowa Orthop J 2005;25:25-9.

4. Charnley J, Eftekhar N. Postoperative infection in total prosthetic replacement arthroplasty of the hip-joint. With special reference to the bacterial content of the air of the operating room. BrJ Surg 1969;56(9):641-9.

5. Lidwell OM. Clean air at operation and subsequent sepsis in the joint. Clin Orthop Relat Res 1986;(211):91-102.

6. Trampuz A, Zimmerli W. Prosthetic joint infections: update in diagnosis and treatment. Swiss Med Wkly 2005;135(17-18):243-51.

7. Little JW, Jacobson JJ, Lockhart PB; American Academy of Oral Medicine. The dental treatment of patients with joint replacements: a position paper from the American Academy of Oral Medicine. J Am Dent Assoc 2010;141(6):667-71.

8. Schutzer SF, Harris WH. Deep-wound infection after total hip replacement under contemporary aseptic conditions. J Bone Joint Surg Am 1988;70(5):724-7.

9. Blackburn WD Jr, Alarcón GS. Prosthetic joint infections. a role for prophylaxis. Arthritis Rheum 1991;34(1):110-7.

10. Goldie MP. New evidence on bacteraemia. Int J Dent Hyg 2010;8(4):317-8.

11. Pizzo G, Guiglia R, Lo Russo L, Campisi G. Dentistry and internal medicine: from the focal infection theory to the periodontal medicine concept. Eur J Intern Med 2010;21(6):496-502. CrossRef

12. Wilson W, Taubert KA, Gewitz M, Lockhart PB, Baddour $\mathrm{LM}$, Levison $\mathrm{M}$, Bolger $\mathrm{A}$, Cabell $\mathrm{CH}$, Takahashi $\mathrm{M}$, Baltimore RS, Newburger JW, Strom BL, Tani LY, Gerber M, Bonow RO, Pallasch T, Shulman ST, Rowley AH, Burns JC, Ferrieri P, Gardner T, Goff D, Durack DT; American Heart Association Rheumatic Fever, Endocarditis, and Kawasaki Disease Committee; American Heart Association Council on Cardiovascular Disease in the Young; American Heart Association Council on Clinical Cardiology; American Heart Association Council on Cardiovascular Surgery and Anesthesia; Quality of Care and Outcomes Research Interdisciplinary Working Group. Prevention of infective endocarditis: guidelines from the American Heart Association: a guideline from the American Heart Association Rheumatic Fever, Endocarditis, and Kawasaki Disease Committee, Council on Cardiovascular Disease in the Young, and the Council on Clinical Cardiology, Council on Cardiovascular Surgery and Anesthesia, and the Quality of Care and Outcomes Research Interdisciplinary Working Group. Circulation 2007;116(15):1736-54.

13. Aas JA, Paster BJ, Stokes LN, Olsen I, Dewhirst FE. Defining the normal bacterial flora of the oral cavity. J Clin Microbiol 2005;43(11):5721-32.

14. Marsh PD. Dental plaque as a biofilm and a microbial community - implications for health and disease. BMC Oral Health 2006;15;6 Suppl 1:S14.
15. Marsh PD. Dental plaque as a microbial biofilm. Caries Res 2004;38(3):204-11.

16. Socransky SS. Relationship of bacteria to the etiology of periodontal disease. J Dent Res 1970;49(2):203-22.

17. Axelsson P, Albandar JM, Rams TE. Prevention and control of periodontal diseases in developing and industrialized nations. Periodontol 2000 2002;29:235-46.

18. Seymour RA, Lowry R, Whitworth JM, Martin MV. Infective endocarditis, dentistry and antibiotic prophylaxis; time for a rethink? Br Dent J 2000;189(11):610-6.

19. Habib G, Hoen B, Tornos P, Thuny F, Prendergast B, Vilacosta I, Moreillon P, de Jesus Antunes M, Thilen $U$, Lekakis J, Lengyel M, Müller L, Naber CK, Nihoyannopoulos P, Moritz A, Zamorano JL; ESC Committee for Practice Guidelines. Guidelines on the prevention, diagnosis, and treatment of infective endocarditis (new version 2009): the Task Force on the Prevention, Diagnosis, and Treatment of Infective Endocarditis of the European Society of Cardiology (ESC). Endorsed by the European Society of Clinical Microbiology and Infectious Diseases (ESCMID) and the International Society of Chemotherapy (ISC) for Infection and Cancer. Eur Heart J 2009;30(19):2369-413. CrossRef

20. Roberts GJ. Dentists are innocent! "Everyday" bacteremia is the real culprit: a review and assessment of the evidence that dental surgical procedures are a principal cause of bacterial endocarditis in children. Pediatr Cardiol 1999;20(5):317-25.

21. Guntheroth WG. How important are dental procedures as a cause of infective endocarditis? Am J Cardiol 1984;54(7):797-801.

22. Harkess JW, Daniels AU. Part III Arthroplasty, Chapter 5: Introduction and Overview. In: Canale ST, Daugherty K., Jones L. editors. Campbell's Operative Orthopaedics 10th ed. USA: Mosby; 2003. p. 223-242.

23. Lockhart PB. Antibiotic prophylaxis for dental procedures: are we drilling in the wrong direction? Circulation 2012;126(1):11-2. CrossRef

24. Antibiotic Prophylaxis for Dental Patients with Total Joint Replacements. AAOS On-Line Service July 1997 Bulletin. Online, Accessed. July 25, 2012. http://www2.aaos.org/ bulletin/jul97/dental.htm

25. American Dental Association; American Academy of Orthopedic Surgeons. Antibiotic prophylaxis for dental patients with total joint replacements. J Am Dent Assoc 2003;134(7):895-9.

26. Ainscow DA, Denham RA. The risk of haematogenous infection in total joint replacements. J Bone Joint Surg $\mathrm{Br}$ 1984;66(4):580-2.

27. Strazzeri JC, Anzel S. Infected total hip arthroplasty due to Actinomyces israelii after dental extraction. A case report. Clin Orthop Relat Res 1986;(210):128-31.

28. Stinchfield FE, Bigliani LU, Neu HC, Goss TP, Foster CR. Late hematogenous infection of total joint replacement. J Bone Joint Surg Am 1980;62(8):1345-50.

29. Barrington JW, Barrington TA. What is the true incidence of dental pathology in the total joint arthroplasty population? J Arthroplasty 2011;26(6 Suppl):88-91. CrossRef

30. Skaar DD, O'Connor H, Hodges JS, Michalowicz BS. Dental procedures and subsequent prosthetic joint infections: findings from the Medicare Current Beneficiary Survey. J Am Dent Assoc 2011;142(12):1343-51. 
31. Berbari EF, Osmon DR, Carr A, Hanssen AD, Baddour LM, Greene D, Kupp LI, Baughan LW, Harmsen WS, Mandrekar JN, Therneau TM, Steckelberg JM, Virk A, Wilson WR. Dental procedures as risk factors for prosthetic hip or knee infection: a hospital-based prospective case-control study. Clin Infect Dis 2010;50(1):8-16. CrossRef

32. D'Ambrosia RD, Shoji H, Heater R. Secondarily infected total joint replacements by hematogenous spread. J Bone Joint Surg Am 1976;58(4):450-3.

33. American Academy of Orthopeadic Surgeons -American Dental Association. Prevention of Orthopaedic Implant Infection in Patients Undergoing Dental Procedures EvidenceBased Guideline and Evidence Report. Online, Accessed. June 15, 2012, http://www.aaos.org/research/guidelines/PUDP/ PUDP_guideline.pdf.
34. Napeñas JJ, Lockhardt PB, Epstein JB. Comment on the 2009 American Academy of Orthopaedic Surgeons' information statement on antibiotic prophylaxis for bacteremia in patients with joint replacements. J Can Dent Assoc 2009;75(6):447-9.

35. Morris AM, Howie S. Recommendations for antibiotics in patients with joint prosthesis are irresponsible and indefensible. J Can Dent Assoc 2009;75(7):513-5. 